Pacific Journal of Mathematic 


\section{ON THE ORDER OF DIRICHLET L-FUNCTIONS}

\section{G. KoLESNIK}

1. Introduction. Let $L(s, \chi)$ be a Dirichlet $L$-function, where $\chi$ is a nonprincipal character $(\bmod q)$ and $s=\sigma+i t$. A standard estimate for $L(s, \chi)$ based on bounds for $\zeta(s, w)$, is

$$
|L(s, \chi)| \leqq C_{1}(\varepsilon) \cdot \tau^{c(1-\sigma)+\varepsilon} q^{1-\sigma}, \quad \frac{1}{2} \leqq \sigma \leqq 1,
$$

where $\tau=|t|+2, c=1 / 6$ (see, for example, Prachar [5, (4.12)]), and in fact, $c$ can be replaced by a constant $<1 / 6$. An immediate application of Richert's work [6] gives

$$
|L(s, \chi)| \leqq C_{1} \tau^{100(1-\sigma) 3 / 2} q^{1-\sigma} \log ^{2 / 3} \tau, \quad \frac{1}{2} \leqq \sigma \leqq 1,
$$

which is better than (1) if $\sigma$ is near 1 .

Another estimate can easily be obtained from $|L(1+i t, \chi)| \leqq$ $C_{2} \log \tau q$ and the functional equation of $L(s, \chi)$ as follows. First,

$$
\begin{aligned}
& |L(i t, \chi)|=2 \cdot \mid(2 \pi)^{i t-1} q^{1 / 2-i t} \\
& \times \cos \frac{1}{2} \pi\left(1-i t+\frac{1}{2}-\frac{1}{2} \bar{\chi}(-1)\right) \Gamma(1-i t) L(1-i t, \bar{\chi}) \mid \\
& \quad \leqq C_{3} \sqrt{\tau q} \log \tau q .
\end{aligned}
$$

Now the convexity principle yields for

$$
\begin{aligned}
|L(s, \chi)| & \leqq\left(C_{3} \sqrt{\tau q} \log \tau q\right)^{1-\sigma} \cdot\left(C_{2} \log \tau q\right)^{\sigma} \leqq C_{4}(\tau q)^{1 / 2(1-\sigma)} \\
& \times \log \tau q, 0 \leqq \sigma \leqq 1
\end{aligned}
$$

Neglecting dependence on $\tau$, Davenport [2], improved (3):

$$
|L(s, \chi)| \leqq C_{2}(\tau) q^{1 / 2(1-\sigma)}, \quad 0 \leqq \sigma \leqq 1 .
$$

Also, Burgess [1] improved (4) by establishing

$$
|L(s, \chi)| \leqq C_{1}(\varepsilon, \tau) q^{3 / 8(1-\sigma)+\varepsilon}, \quad \frac{1}{2} \leqq \sigma \leqq 1 .
$$

By examining Burgess' proof, it can be seen that the constant $C(\varepsilon, \tau)$ can be taken to be $C_{2}(\varepsilon) \pi^{2(1-\sigma)}$ and his result can be further sharpened to yield

$$
|L(s, \chi)| \leqq C_{6} \tau^{2(1-\sigma)} q^{3 / 8(1-\sigma)} C^{\omega} \log \tau, \quad \frac{1}{2} \leqq \sigma \leqq 1,
$$


where $\omega=\log q / \log \log q$. The estimates (3), (4), and (5) are better than (1) if $q$ is large compared to $\tau$.

For $\sigma=1 / 2$, the previous estimates were improved by Fujii, Gallagher and Montgomery, [3], who showed that if $P$ is a fixed set of primes and $q$ is composed only of primes in $P$, then

$$
\left|L\left(\frac{1}{2}+i t, \chi\right)\right| \leqq C(\varepsilon, P)(\tau q)^{1 / 6+\varepsilon} .
$$

In this paper we prove two more estimates which imply (1), (4), and (5) and which are better than (2), (3), and (6) in some range of $\sigma, \tau$, and $q$. We prove:

THEOREM 1. Let $\chi$ be a nonprincipal character $(\bmod q)$. Let $1 / 2 \leqq \sigma \leqq 1, \tau=|t|+2$ and $\omega=\log q / \log \log q$. Then

$$
|L(s, \chi)| \ll \tau^{-\sigma} q^{3 / 8(1-\sigma)} C^{\omega} \log \tau,
$$

where $C$ is some absolute constant.

THEOREM 2. Let $\chi$ be a character $(\bmod q)$. Let $1 / 2 \leqq \sigma \leqq 1$ and $\tau=|t|+2$. Then

$$
|L(s, \chi)| \ll \tau^{35 / 108(1-\sigma)} q^{1-\sigma} \log ^{3} \tau q .
$$

In particular, (7) and (8) imply

$$
\mid L\left(\frac{1}{2}+i t, \chi \mid\right) \ll \sqrt{\tau} q^{3 / 16} C^{\omega} \log \tau
$$

and

$$
\left|L\left(\frac{1}{2}+i t, \chi\right)\right| \ll \tau^{35 / 216} \sqrt{q} \log ^{3} \tau q .
$$

The estimates of $L(s, \chi)$ for $\sigma \in[0,1 / 2]$ can be obtained by using (7) or (8) and the functional equation of $L(s, \chi)$.

The author expresses his gratitude to Professors P. X. Gallagher and Lowell Schoenfeld for valuable suggestions.

\section{Notation.}

$$
\begin{aligned}
e(f(x)) & =\exp (2 \pi i f(x)) \\
\omega & =\log q / \log \log q . \\
s & =\sigma+i t, \frac{1}{2} \leqq \sigma \leqq 1 \\
\tau & =|t|+2 .
\end{aligned}
$$


$C$ denotes some appropriate absolute constant, not always the same.

3. Application of the estimate of Burgess. In this section we will show that

$$
|L(s, \chi)| \ll \pi^{1-\sigma} q^{3 / 8(1-o)} C^{\omega} \log ^{3} \tau .
$$

We need the following result of E. Bombieri:

Lemma. Let $N$ and $m$ be nonnegative integers. Let $\alpha_{j}, \beta_{j}$ be numbers such that $\left|\alpha_{j}-\beta_{j}\right| \leqq\left(2 \pi m N^{j}\right)^{-1}$ for $1 \leqq j \leqq m$, and let $f(x)=\alpha_{1} x+\cdots+\alpha_{m} x^{m}, \quad g(x)=\beta_{1} x+\cdots+\beta_{m} x^{m}$. Let $c_{1}, c_{2}, \cdots$ be complex, and let

$$
S(\bar{\alpha}, N)=\max _{1 \leqq N_{1}<N}\left|\sum_{1 \leqq n \leqq N_{1}} c_{n} e(f(n))\right|,
$$

where $\bar{\alpha}=\left(\alpha_{1}, \cdots, \alpha_{m}\right)$. Then $S(\bar{\beta}, N) \leqq 6 S(\bar{\alpha}, N)$.

Proof. For every $N_{1} \in[1, N]$ we have:

$$
\begin{aligned}
& \sum_{1 \leqq n \leqq N_{1}} c_{n} e(g(n))=\sum_{1 \leqq n \leqq N_{1}} c_{n} e(f(n)) \prod_{j=1}^{m} e\left(\left(\beta_{j}-\alpha_{j}\right) n^{j}\right) \\
& \quad=\sum_{k_{1}, \cdots, k_{m}=0}^{\infty}\left(\prod_{j=1}^{m} \frac{\left\{2 \pi i\left(\beta_{j}-\alpha_{j}\right)\right\}^{k_{j}}}{k_{j} !}\right) \sum_{1 \leqq n \leqq N_{1}} c_{n} n^{m k_{m}+\ldots+k_{1}} e(f(n)) .
\end{aligned}
$$

Using Abel's summation formula, we obtain:

$$
\begin{aligned}
S(\bar{\beta}, N) & \leqq \sum_{k_{1}, \ldots, k_{m}=0} \prod_{j=1}^{m} \frac{\left|2 \pi\left(\beta_{j}-\alpha_{j}\right)\right|^{k_{j}}}{k_{j} !} \cdot N^{m k_{m}+\ldots+k_{1}} \cdot 2 S(\bar{\alpha}, N) \\
& \leqq 2 S(\bar{\alpha}, N) \cdot \sum_{k_{1}, \ldots, k_{m}=0}^{\infty} \prod_{j=1}^{m} \frac{\mid\left(\left.2 \pi\left(\beta_{j}-\alpha_{j}\right) N^{j}\right|^{k_{j}}\right.}{k_{j} !} \\
& \leqq 2 S(\bar{\alpha}, N)\left(\sum_{k=0}^{\infty} m^{-k} / k !\right)^{m} \leqq 6 S(\bar{\alpha}, N) .
\end{aligned}
$$

Lemma 2. Let $q \geqq 2$ and let $M, N$ be integers. Let $\chi$ be a primitive character $(\bmod q)$. Then

$$
\left|\sum_{1 \leqq n \leqq N} \chi(n+M)\right| \leqq V \bar{N} q^{3 / 16} C^{\omega} .
$$

This lemma can be proven similarly to Theorem 2, [1].

LeMma 3. Let $q$ and $N$ be integers such that $q \geqq 2$ and $N \leqq \tau q$. Let $\chi$ be a primitive character $(\bmod q)$. Then

$$
\left|S=\max _{N \leqq N_{1} \leqq 2 N}\right| \sum_{N+1 \leqq n \leqq N_{1}} \chi(n) n^{-i t} \mid \ll \sqrt{N \tau \log \tau} \cdot q^{3 / 16} C^{\omega} .
$$


Proof. We can obviously suppose that $\tau \log \tau q \leqq N$ since otherwise the estimate is trivial. Taking $H=\left[N(\tau \log \tau q)^{-1}\right]$ and $m=$ $[\log \tau q]$, and dividing the sum in $S$ into $\leqq 2 N H^{-1}$ subsums, we obtain:

$$
|S| \leqq 2 N H^{-1} \max _{N \leqq M \leqq 2 N} \max _{1 \leqq H_{1} \leqq H}\left|\sum_{M+1 \leqq n \leqq M+H I_{1}} \chi(n) n^{-i t}\right| .
$$

For every $M$ and $H_{1}$ in the above range, we get

$$
\begin{aligned}
& \quad \sum_{M+1 \leqq n \leqq M+H_{1}} \chi(n) n^{-i t}|=| \sum_{1 \leqq n \leqq H_{1}} X(n+M)\left(\frac{n+M}{M}\right)^{-i t} \mid \\
& \leqq \\
& \qquad \sum_{1 \leqq n \leqq H_{1}} \chi(n+M) e\left(-\frac{t}{2 \pi}\left\{\frac{n}{M}-\frac{n^{2}}{2 M^{2}}+\cdots+\frac{(-1)^{m} \cdot n^{m}}{m M^{m}}\right\}\right) \mid \\
& +\frac{|t| H^{m+2}}{M^{m+1}} .
\end{aligned}
$$

Let $\beta_{j}=0$ and $\alpha_{j}=(-1)^{j} t / 2 \pi j M^{j}$. Then for $1 \leqq j \leqq m\left|\alpha_{j}-\beta_{j}\right|=$ $|t| \cdot\left(2 \pi j M^{j}\right)^{-1} \leqq\left(2 \pi m H^{j}\right)^{-1}$. Applying Lemmas 1 and 2 , we obtain:

$$
\begin{aligned}
|S| \leqq\left|2 N H^{-1} \max _{N \leqq M \leqq 2 N} \max _{1 \leqq H_{1} \leqq H}\right| \sum_{1 \leqq n \leqq H} \chi(n+M) \mid+2 \frac{\tau H^{m+1}}{N^{m}} \\
\ll N H^{-1} \sqrt{H} q^{3 / 16} C^{\omega}+N \tau(\tau \log \tau q)^{-\log \tau q} \\
\ll \sqrt{N \cdot \tau \log \tau q} q^{3 / 16} C^{\omega} .
\end{aligned}
$$

From this, the result is easily obtained.

Now we can prove Theorem 1. First, we suppose that $\chi$ is primitive. Let $N=[\tau q], \quad M=\left[\tau q^{3 / 8}\right], \quad L=\log (N / M) / \log 2, \quad N_{l}=$ $M 2^{l}(l=0, \cdots, L)$. Using Abel's formula, the Polya-Vinogradov estimate for character sums and Lemma 3, we get:

$$
\begin{aligned}
& |L(s, \chi)| \leqq \sum_{n<s} n^{-\sigma}+\left|\sum_{M \leqq n \leqq N} \chi(n) n^{-\sigma-i t}\right|+\left|\sum_{n>N} \chi(n) n^{-s}\right| \\
& \ll M^{1-\sigma} \log M+\sum_{l=0}^{L} \max _{N_{l} \leqq N_{l}^{1} \leqq 2 N_{l}}\left|\sum_{N_{l} \leqq n \leqq N_{l}^{1}} \chi(n) n^{-\sigma-i t}\right| \\
& \quad+\sum_{n>N} \tau n^{-\sigma-1}\left|\sum_{N \leqq x \leqq n} \chi(n)\right| \\
& \ll M^{1-\sigma} \log M+\sum_{l=0}^{L} N_{l}^{-\sigma} \max _{N_{l} \leqq N_{l}^{1} \leqq 2 N_{l}}\left|\sum_{N_{l} \leqq n \leqq N_{l}^{1}} \chi(n)^{-i t}\right| \\
& \quad+\tau \sqrt{q} N^{-\sigma} \log q \\
& \ll M^{1-\sigma} \log M+\sum_{l=0}^{L} N_{l}^{1 / 2-\sigma} \sqrt{\tau} q^{3 / 16} C^{\omega} \sqrt{\log \tau}+\tau \sqrt{q} N^{-\sigma} \log q \\
& \ll M^{1-\sigma} \log M+L M^{1 / 2-\sigma} \sqrt{\tau} q^{3 / 18} C^{\omega} \sqrt{\log \tau}+\tau \sqrt{q} N^{-\sigma} \log q \\
& \ll \tau^{1-\sigma} q^{3 / 8(1-\sigma)} C^{\omega} \log \tau .
\end{aligned}
$$

If $X$ is not primitive, then there is a $q_{1} \mid q$ and a primitive 
character $\chi_{1}\left(\bmod q_{1}\right)$, associated with $\chi$, such that we can write (see, for example, $[5,(6.12)])$ :

$$
|L(s, \chi)|=\left|L\left(s, \chi_{1}\right)\right| \prod_{p \mid q}\left|1-\frac{\chi_{1}(p)}{p^{s}}\right| \leqq\left|L\left(s, \chi_{1}\right)\right| \cdot \prod_{p \mid q} 2 \leqq\left|L\left(s, \chi_{1}\right)\right| \cdot 2^{\omega},
$$

and the theorem follows.

4. The proof of Theorem 2. To prove Theorem 2, we need two lemmas.

LEMmA 4. Let $t \geqq 0,0 \leqq a \leqq 1$, and let $X$ and $X_{1}$ be integers such that $0<X \leqq X_{1} \leqq 2 X \leqq \tau^{143 / 108}$. Then

$$
S_{1} \equiv \sum_{X \leqq x \leqq X_{1}} e(t \log (x+a)) \ll \sqrt{X} \tau^{35 / 216} \log ^{2} \tau .
$$

Proof. If $X \leqq \sqrt{\tau}$, then the result can be proven similarly to Corollary 2, [4]. The same method yields

$$
\sum_{X \leqq x \leqq X_{1}} e(t \log x-a x) \ll \sqrt{X} \tau^{35 / 216} \log ^{2} \tau,
$$

for $X \leqq \sqrt{\pi}$. If $\sqrt{\tau} \leqq X \leqq \tau^{143 / 108}$, then, by Lemma 3 of [4]

$$
\left|S_{1}\right| \leqq \sum_{t /\left(X_{1}+a\right) \leqq n \leqq t /\langle X+a)} \frac{\sqrt{t}}{n} e(t \log n-a n) \mid+0\left(X \tau^{-1 / 2}\right) .
$$

Here $t /(X+a) \leqq \sqrt{\tau}$. With the use of Abel's inequality, (9) yields the result for $\sqrt{\tau} \leqq X \leqq \tau^{143},{ }^{108}$.

LemmA 5 . Let $1 / 2 \leqq \sigma \leqq 1, t \geqq 1$ and $0 \leqq a \leqq 1$. Then

$$
\zeta(s, a) \equiv \sum_{n=0}^{\infty}(n+a)^{-s} \ll a^{-\sigma}+\tau^{35(1-\sigma) / 108} \log ^{3} \tau .
$$

Proof. Let $N=\tau^{143 / 108}$. Using the Euler-Maclaurin formula [see, for example, [5], (1.7), p. 372]), we obtain similarly to [5], (5.8), p. 114:

$$
\begin{aligned}
& \zeta(s, a)-\sum_{n=0}^{N-1}(n+a)^{-s}=\frac{(N+a)^{1-s}}{1-s}-s \int_{N}^{\infty} \frac{x-[x]}{(x+a)^{s+1}} d x \\
& =\frac{(N+a)^{1-s}}{1-s}-\frac{1}{2} s \frac{(x-[x])^{2}}{(x+a)^{s+1}} \int_{N}^{\infty}+\frac{1}{2} s(s+1) \int_{N}^{\infty} \frac{(x-[x])^{2}}{(x+a)^{s+2}} d x \\
& \ll 1+\tau^{2} \int_{N}^{\infty} u^{-\sigma-2} d u \leqq 1+\tau^{2} \cdot N^{-\sigma-1} \ll \tau^{35(1-\sigma) / 108} .
\end{aligned}
$$

If we denote $M=\left[\tau^{35 / 108}\right], \quad L=[\log (N / M) / \log 2], \quad N_{l}=M \cdot 2^{l}$ for $l=0, \cdots, L$ and $N_{L+1}=N$, then we have 


$$
S \equiv \sum_{n=0}^{N-1}(n+a)^{-s} \ll \sum_{0<n<M}(n+a)^{-\sigma}+\sum_{0 \leqq l \leqq L}\left|\cdot \sum_{N_{l} \leqq n<N_{l+1}}(n+a)^{-s}\right| .
$$

Using Abel's formula and Lemma 4, we obtain:

$$
\begin{aligned}
S \ll & a^{-\sigma}+M^{1-\sigma} \log M+\sum_{0 \leqq l \leqq L} N_{l}^{-\sigma} \max _{N_{l} \leqq N_{l}^{\prime} \leqq N_{l+1}}\left|\sum_{N_{l} \leqq n \leqq N_{l}^{\prime}}(n+a)^{-i t}\right| \\
\ll & a^{-\sigma}+M^{1-\sigma} \log M+\sum_{0 \leqq l \leqq L} N_{l}^{1 / 2-\sigma} \cdot \tau^{35 / 216} \log ^{2} \tau \ll a^{-\sigma} \\
& \quad+\tau^{35(1-\sigma) / 108} \log ^{3} \tau .
\end{aligned}
$$

This proves the lemma.

To prove Theorem 2 , we can obviously suppose $t \geqq 1$, otherwise the result follows from (1). Using Lemma 5, we obtain:

$$
\begin{aligned}
& |L(s, \chi)|=\left|q^{-s} \sum_{m=1}^{q} \chi(m) \zeta(s, m / q)\right| \\
& \quad<q^{-\sigma} \sum_{m=1}^{q}\left((q / m)^{\sigma}+\tau^{35(1-\sigma) / 108} \log ^{3} \tau\right) \ll \tau^{35(1-\sigma) / 108} q^{1-\sigma} \log ^{3} \tau q .
\end{aligned}
$$

Note Added in Proof. We would like to draw attention to a recent paper by D. R. Heath-Brown, "Hybrid bounds for Dirichlet $L$-function," Inventiones Mathematicae, 44 (1978), 149-170, which contains a better result than our Theorem 7 .

\section{REFERENCES}

1. D. A. Burgess, On character sums and L-series, II, Proc. London Math. Soc., (3), 13 (1963), 524-536.

2. H. Davenport, On Dirichlet's L-function, J. London Math. Soc., 6 (1931), 198-202.

3. A. Fujii, P. X. Gallagher, H. L. Montgomery, Some hybrid bounds for character sums and Dirichlet L-series, Colloquia Math. Soc. Janos Bolyai, 13 (1974), 41-57.

4. G. Kolesnik, On the order of $\zeta(1 / 2+i t)$ and $L(R)$, Pacific J. of Math., submitted.

5. K. Prachar, Primzahlverteilung, Springer-Verlag, 1957.

6. H. E. Richert, Zur Abschätzung der Riemannschen Zetafunction in der Nähl der Vertikalen $\sigma=1$, Math. Ann., 169 (1967), 97-101.

Received January 25, 1977.

California Institute of Technology

PAsadena, CA 91125

AND

State University of New York at Buffalo

Buffalo, NY 14214 


\section{PACIFIC JOURNAL OF MATHEMATICS}

\section{EDITORS}

Donald BABBITT (Managing Editor)

University of California

Los Angeles, CA 90024

HUGo RossI

University of Utah

Salt Lake City, UT 84112

C. C. MOORE and ANDREW OGG

University of California

Berkeley, CA 94720

\section{J. DuGUNDJI}

Department of Mathematics

University of Southern California

Los Angeles, CA 90007

R. FINN and J. Milgram

Stanford University

Stanford, CA 94305

ASSOCIATE EDITORS
E. F. BECKENBACH
B. H. NeumanN
F. WOLF
K. YoSHIDA

\section{SUPPORTING INSTITUTIONS}

\author{
UNIVERSITY OF BRITISH COLUMBIA \\ CALIFORNIA INSTITUTE OF TECHNOLOGY \\ UNIVERSITY OF CALIFORNIA \\ MONTANA STATE UNIVERSITY \\ UNIVERSITY OF NEVADA, RENO \\ NEW MEXICO STATE UNIVERSITY \\ OREGON STATE UNIVERSITY \\ UNIVERSITY OF OREGON
}

\author{
UNIVERSITY OF SOUTHERN CALIFORNIA \\ STANFORD UNIVERSITY \\ UNIVERSITY OF HAWAII \\ UNIVERSITY OF TOKYO \\ UNIVERSITY OF UTAH \\ WASHINGTON STATE UNIVERSITY \\ UNIVERSITY OF WASHINGTON
}

The Supporting Institutions listed above contribute to the cost of publication of this Journal, but they are not owners or publishers and have no responsibility for its content or policies.

Mathematical papers intended for publication in the Pacific Journal of Mathematics should be in typed form or offset-reproduced, (not dittoed), double spaced with large margins. Please do not use built up fractions in the text of the manuscript. However, you may use them in the displayed equations. Underline Greek letters in red, German in green, and script in blue. The first paragraph or two must be capable of being used separately as a synopsis of the entire paper. Please propose a heading for the odd numbered pages of less than 35 characters. Manuscripts, in triplicate, may be sent to any one of the editors. Please classify according to the scheme of Math. Reviews, Index to Vol. 39. Supply name and address of author to whom proofs should be sent. All other communications should be addressed to the managing editor, or Elaine Barth, University of California, Los Angeles, California, 90024.

50 reprints to each author are provided free for each article, only if page charges have been substantially paid. Additional copies may be obtained at cost in multiples of 50 .

The Pacific Journal of Mathematics is issued monthly as of January 1966. Regular subscription rate: $\$ 84.00$ a year (6 Vols., 12 issues). Special rate: $\$ 42.00$ a year to individual members of supporting institutions.

Subscriptions, orders for numbers issued in the last three calendar years, and changes of address should be sent to Pacific Journal of Mathematics, P.O. Box 969, Carmel Valley, CA 93924, U.S.A. Older back numbers obtainable from Kraus Periodicals Co., Route 100, Millwood, NY 10546.

PUBLISHED BY PACIFIC JOURNAL OF MATHEMATICS, A NON-PROFIT CORPORATION

Printed at Kokusai Bunken Insatsusha (International Academic Printing Co., Ltd.). 8-8, 3-chome, Takadanobaba, Shinjuku-ku, Tokyo 160, Japan.

Copyright (C) 1979 by Pacific Journal of Mathematics Manufactured and first issued in Japan 


\section{Pacific Journal of Mathematics}

\section{Vol. 82 , No. 2 \\ February, 1979}

Krishnaswami Alladi and Paul Erdős, On the asymptotic behavior of large prime

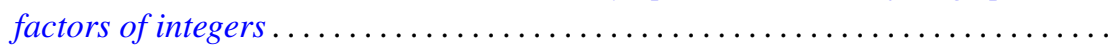

Alfred David Andrew, A remark on generalized Haar systems in $L_{p}$,

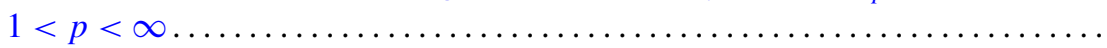

John M. Baker, A note on compact operators which attain their norm . . ........

Jonathan Borwein, Weak local supportability and applications to

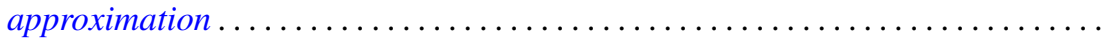

Tae Ho Choe and Young Soo Park, Wallman's type order compactification ........

Susanne Dierolf and Ulrich Schwanengel, Examples of locally compact

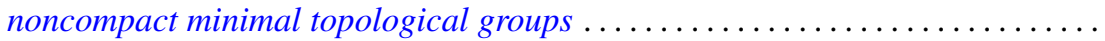

Michael Freedman, A converse to (Milnor-Kervaire theorem) $\times R$ etc. . . . . . . .

George Golightly, Graph-dense linear transformations ..................

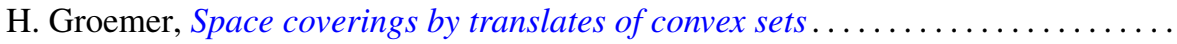

Rolf Wim Henrichs, Weak Frobenius reciprocity and compactness conditions in

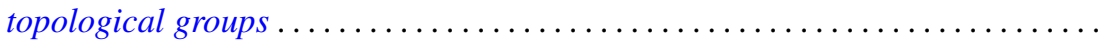

Horst Herrlich and George Edison Strecker, Semi-universal maps and universal

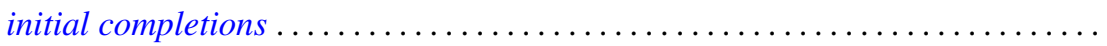

Sigmund Nyrop Hudson, On the topology and geometry of arcwise connected,

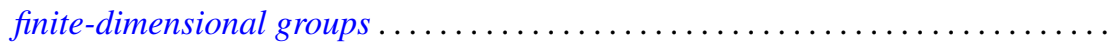

K. John and Václav E. Zizler, On extension of rotund norms. II .............

Russell Allan Johnson, Existence of a strong lifting commuting group of transformations. II.

Bjarni Jónsson and Ivan Rival, Lattice varieties covering the smallest nonmodular variety

Grigori Abramovich Kolesnik, On the order of Dirichlet L-functions .

Robert Allen Liebler and Jay Edward Yellen, In search of nonsolvable groups of

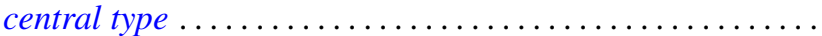

Wilfrido Martínez T. and Adalberto Garcia-Maynez Cervantes, Unicoherent plane Peano sets are $\sigma$-unicoherent ...

M. A. McKiernan, General Pexider equations. I. Existence of injective

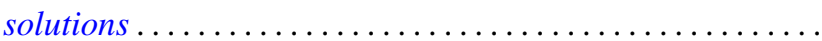

M. A. McKiernan, General Pexider equations. II. An application of the theory of webs.

Jan K. Pachl, Measures as functionals on uniformly continuous functions . .

Lee Albert Rubel, Convolution cut-down in some radical convolution algebras ...

Peter John Slater and William Yslas Vélez, Permutations of the positive integers

with restrictions on the sequence of differences. II . . .

Raymond Earl Smithson, A common fixed point theorem for nested spaces ....

Indulata Sukla, Generalization of a theorem of McFadden .... . . .

Jun-ichi Tanaka, A certain class of total variation measures of analytic measures.

Kalathoor Varadarajan, Modules with supplements .............. 